\title{
Relação professor-estudante na educação superior: suporte social e habilidades sociais
}

\author{
Teacher-student relationship in higher education: \\ social support and social skills
}

\author{
Joene Vieira-Santos (D*, Almir Del Prette (D**, Zilda A. P. Del Prette (D**, Leandro S. Almeida (D*** \\ Centro Universitário Adventista de São Paulo, **Universidade Federal de São Carlos, \\ ***Universidade do Minho
}

\begin{abstract}
Resumo
Uma das tarefas do professor é criar condições para a aprendizagem e sucesso acadêmico do aluno, o que inclui a oferta de suporte social (SS). SS está relacionado à qualidade da relação estabelecida com um outro significativo que se mostra disponível para cuidar, valorizar e fortalecer a percepção de pertencimento do indivíduo. Nesse sentido, as habilidades sociais de fazer e manter amizades, empatia e solidariedade parecem estar na base dos padrões comportamentais usualmente entendidos como SS. O presente estudo investigou a avaliação que universitários brasileiros fazem da frequência com que seus professores apresentam tais habilidades. Foram analisadas as respostas fornecidas por 1406 estudantes aos 10 itens do Inventário de Habilidades Sociais Educativas do Professor Universitário - versão Aluno (IHSE-PU-Aluno) relacionados ao SS. Os dados evidenciaram que, no geral, os professores fornecem SS aos seus alunos. Contudo, ao cruzar os resultados sobre SS com características da amostra, observou-se que na percepção dos alunos: (a) professores de instituições particulares ofereciam mais SS do que os de instituições públicas; e (b) professores que desempenham a função de supervisor (estágio ou pesquisa) oferecem mais SS do que aqueles que não desempenham tal função. Uma vez que o SS oferecido pelos professores impacta na adaptação e permanência dos estudantes, importa aprofundar em futuros estudos as variáveis que afetam a sua percepção sobre o SS recebido dos professores.
\end{abstract}

Palavras-chave: habilidades sociais, relação professor-aluno, suporte social, educação superior

Joene Vieira-Santos (D), Centro Universitário Adventista de São Paulo - Campus Hortolândia (UNASP-HT). Rua Pr. Hugo Gegembauer, 265. Cep 13184-010/Hortolândia - SP - Brasil.

Almir Del Prette (D) \& Zilda A. P. Del Prette (D), Universidade Federal de São Carlos, Departamento de Psicología, Via Washington Luis km 235, Caixa Postal 676 CEP 13565-905, São Carlos, SP, Brasil.

Leandro S. Almeida (D), Centro de Investigação em Educação, Instituto de Educação, Universidade do Minho. Campus de Gualtar, 4710075 Braga, Portugal.

Correspondência relativa a este artigo: Joene Vieira-Santos - joenesantos@yahoo.com.br 


\begin{abstract}
One of the tasks of the teacher is to create conditions for student learning and academic success, that includes offering social support (SS). SS is directly related to the quality of the relationship established with a significant other that is available to care, to appreciate and strengthen the individual's perception of belonging. This sense, the social skills of making and keeping friendships, empathy and solidarity seem to be at the base on behavioural pattern usually understood as SS. The present study investigates the evaluation that Brazilians universities students of the frequency with which their college teachers show these skills. The responses of 1406 students to the items of the Educative Social Skills Inventory (ESSI) for College Teacher - student version (ESSI-CTStudent) related to SS were analysed. The data show that, in general, teachers make SS to their students. And, when crossing the results of the studies with characteristics of the sample, it was observed that in the students' perception: (a) teachers of private institutions offered more SS than those of public institutions; and (b) teachers who perform the function of supervisor (internship or research) offer more SS than those who do not perform such function. Once the SS offered by the teachers impacts on the adaptation and permanence of the students, it is important to study in depth the variables that affect their perception of the SS received from the teachers.
\end{abstract}

Keywords: social skills, teacher-student relationship, social support, higher education

O ingresso na Educação Superior, o processo de adaptação a essa nova realidade acadêmica e a permanência no sistema até concluir o curso envolvem vários desafios para o estudante. Primeiramente, a realidade acadêmica da Educação Superior é bem diferente da realidade do Ensino Médio. De acordo com Soares et al. (2014), quando se compara as atividades curriculares do Ensino Médio e da Educação Superior, observa-se que na universidade as atividades são "menos sequenciadas e menos apoiadas num livro de texto ou manual, os horários são mais flexíveis, os professores são mais distantes e novas amizades terão que ser construídas na base de um conjunto bastante alargado e heterogêneo de colegas desconhecidos” (p. 49). A Educação Superior requer dos alunos níveis crescentes de autonomia e de autorregulação na sua aprendizagem (Baranovskaya, 2015).

Aliado a isso, os professores universitários, em sua maioria, utilizam metodologias de ensino que diferem bastante daquelas utilizadas no Ensino Médio, requerendo níveis superiores de responsabilidade e maturidade dos alunos (Matta, Lebrão, \& Heleno, 2017). O controle menos rígido quanto a frequência, bem como a faixa etária dos estudantes (a maioria sendo jovem-adulto ou adulto), contribui para que os professores exijam uma participação mais ativa e responsável dos alunos no processo de aprendizagem.

A Educação Superior também envolve o desafio de desenvolver uma série de competências, conhecimentos, atitudes e valores que serão necessárias para o exercício da futura profissão. Nessa direção, Marinho-Araujo e Almeida (2016) ressaltam a importância da Educação Superior proporcionar condições para uma formação cidadã, voltada para o desenvolvimento, no aluno, do compromisso ético, político e crítico com questões importantes relativas aos aspectos sociais, econômicos e culturais da comunidade. Esses autores defendem que a universidade deve promover condições para o estudante desenvolver competências transversais, as quais agrupam-se em três dimensões: (a) recursos pessoais, entendidos como características, conhecimentos e recursos do indivíduo voltados para o desenvolvimento pessoal e profissional; (b) recursos socioafetivos, relacionados às características que favorecem o estabelecimento de relacionamentos interpessoais e de espaços de interlocução para a atuação profissional; e (c) e recursos éticopolíticos, ou seja, características que favorecem à resolução de situações potencialmente conflituosas e que não estão pautadas em juízos de valores ou normas moralistas discriminatórias que geram exclusão social.

Outro desafio decorre de muitos alunos abandonarem a sua cidade de origem para frequentar a universidade, emergindo dificuldades relacionadas a distância da família e amigos de longa data, de morar sozinho ou com pessoas desconhecidas e de sobreviver em uma cidade desconhecida e, algumas vezes, um ambiente cultural mais urbano face aos contextos de interior e rurais de proveniência. Em muitos casos, o estudante acaba 
por ir residir na residência estudantil da universidade ou em uma república (residência compartilhada com outros estudantes) e precisa aprender a "dividir quarto com pessoas desconhecidas, partilhar espaços coletivos com vários moradores (...), desenvolver habilidades para construir novas amizades, conviver com a distância da família e amigos e enfrentar dificuldades financeiras para se manter na universidade" (Jesus, Schneider, Barbosa, Simon, \& Steglich, 2017, p. 71).

Todos esses desafios podem levar o estudante a questionar vários domínios de sua experiência, tais como a escolha da carreira, valores e atitudes, sua forma de aprender e produzir conhecimentos, a maneira como se relaciona com pessoas que pensam igual ou diferente de si, entre outros (Matta et al., 2017; Pascarella \& Terenzini, 2005). Nesse contexto, um fator que favorece a permanência do estudante na Educação Superior refere-se ao suporte social que ele recebe (López, 2016), quer seja da família (Dorrance Hall et al., 2017; Strom \& Savage, 2014), de amigos/pares (Henninger IV, Eshbaugh, Osbeck, \& Madigan, 2016) ou de profesores (Hagenauer \& Volet, 2014; Oliveira, Wiles, Fiorin, \& Dias, 2014; Pascarella \& Terenzini, 2005).

O termo suporte social (SS) foi definido por Sarason, Levine, Basham e Sarason (1983) como "a existência ou disponibilidade de pessoas em quem podemos confiar, que nos deixam entender que se preocupam conosco, que nos valorizam e que gostam de nós" (p. 127). É um construto complexo e multidimensional associado à saúde e ao bem-estar do indivíduo e que auxilia no entendimento de como as diferentes relações influenciam positiva ou negativamente na forma como alguém enfrenta as adversidades ao longo da vida (Marôco, Campos, Vinagre, \& Pais-Ribeiro, 2014). Cobb (1976) sugere que o SS envolve três classes de informações: (a) aquelas que levam a pessoa a crer que é cuidada e amada, (b) aquelas que permitem que a pessoa acredite que é estimada e valorizada e (c) aquelas que fazem com que a pessoa perceba que pertence a uma rede de comunicação e obrigações mútuas.

Um aspecto que parece central na compreensão de SS é o fato de estar diretamente ligado à relação estabelecida com um outro (ou outros) significativo que se mostra disponível para cuidar, valorizar e fortalecer a percepção de pertencimento do indivíduo. Nessa direção, pensando especificamente na relação professor-aluno, os dados encontrados por Hagenauer e Volet (2014) parecem ser bastante relevantes. Esses autores, ao revisar a literatura sobre a relação professor-aluno no contexto da Educação Superior, observaram que a qualidade dessa relação depende de duas dimensões amplas: afetividade e suporte. A primeira refere-se ao vínculo construído entre alunos e professores e está baseada nas relações vivenciadas como seguras e positivamente afetivas. Tal dimensão requer, por parte do professor, comportamentos de cuidado e respeito para com os alunos, bem como a promoção da integração dos alunos com o ambiente acadêmico (pesquisa, laboratórios), com pares e com professores.

A segunda dimensão proposta por Hagenauer e Volet (2014) refere-se ao suporte que deve ser oferecido, a partir da relação professor-aluno, para o sucesso acadêmico do estudante. Nessa dimensão estão incluídos os comportamentos de aproximar-se do aluno e de oferecer ajuda de uma maneira "balanceada", ou seja, tomando em consideração os padrões comportamentais apropriados para os papéis de docente e aluno. Portanto, esses dados parecem indicar que uma das tarefas envolvidas no papel de professor é a de criar condições para a aprendizagem e sucesso acadêmico do aluno, o que inclui oferecer SS ao estudante.

Dentro da Psicologia, o campo teórico-prático das habilidades sociais tem se dedicado a investigar os comportamentos e as condições que colaboram para o estabelecimento de interações sociais satisfatórias e baseadas em valores de convivência (A. Del Prette \& Del Prette, 2010a, 2017a). Assim, uma vez que a qualidade da relação parece ser um ponto central para o SS, é possível que essa área da Psicologia possa contribuir para uma leitura sobre como determinados comportamentos apresentados pelo professor, na relação com o seu aluno, podem caracterizar como SS.

De acordo com A. Del Prette e Del Prette (2017), as habilidades sociais (HS) são comportamentos sociais (ou seja, apresentados na relação com o outro) que estão em consonância com os valores de respeito mútuo compartilhados por uma determinada cultura/comunidade e que possuem alta probabilidade de gerar resultados 
favoráveis aos envolvidos (indivíduo, grupo e comunidade), contribuindo para a manutenção e qualidade da relação. Ao longo da vida, um indivíduo desempenha diferentes papéis sociais, os quais "(...) são culturalmente determinados e envolvem padrões de comportamentos esperados pelo grupo social (ou autoatribuídos) no exercício de determinadas funções em contextos e atividades específicas” (A. Del Prette \& Del Prette, 2017a, p. 69). Um determinado papel social pode requerer um repertório complexo e elaborado de HS para atender as diversas tarefas interpessoais envolvidas no mesmo.

Pensando na atuação docente na Educação Superior, uma das tarefas envolvidas no papel de professor é a de criar condições para a aprendizagem e sucesso acadêmico do aluno (Weimer, 2002), o que envolve oferecer SS aos seus alunos. Então, uma pergunta que surge é: quais HS estariam mais envolvidas no comportamento de cuidar, valorizar e fortalecer a percepção de pertencimento do indivíduo? A partir da análise da literatura, A. Del Prette e Del Prette (2017a) propuseram um conjunto amplo de HS que podem ser importantes para diversos papéis sociais que podem ser assumidos ao longo da vida. Tomando como base essa classificação e a função de cada categoria, três classes de HS parecem estar relacionadas ao SS: fazer e manter amizades, empatia e solidariedade.

A primeira classe diz respeito aos comportamentos que são requeridos para estabelecer e manter uma relação de proximidade com outra pessoa, envolvendo:

Iniciar conversação, apresentar informações livres, ouvir/fazer confidências, demonstrar gentileza, manter contato sem ser invasivo, expressar sentimentos, elogiar, dar feedback, responder a contato, enviar mensagem (e-mail, bilhete, WhatsApp), convidar/aceitar convite para passeio, fazer contatos em datas festivas (aniversário, Natal, etc.), manifestar solidariedade diante de problemas. (p. 28)

Expressar empatia refere-se aos comportamentos necessários para compreender a perspectiva e necessidades do outro, o que inclui:

Manter contato visual, aproximar-se do outro, escutar (evitando interromper), tomar perspectiva (colocar-se no lugar do outro), expressar compreensão, incentivar a confidência (quando for o caso), demonstrar disposição para ajudar (se for o caso), compartilhar alegria e realização do outro (nascimento do filho, aprovação no vestibular, obtenção de emprego, etc.) (p. 28).

E, por fim, expressar solidariedade está relacionado a oferta de ajuda/apoio ao outro e envolve comportamentos de: Identificar necessidades do outro, oferecer ajuda, expressar apoio, engajar-se em atividades sociais construtivas, compartilhar alimentos ou objetos com pessoas deles necessitadas, cooperar, expressar compaixão, participar de reuniões e campanhas de solidariedade, fazer visitas a pessoas com necessidades, consolar, motivar colegas a fazer doações (p. 29).

A importância dessas classes de HS para a qualidade da relação professor-aluno e, consequentemente, para o SS oferecido pelo professor ao estudante parece estar implícita nos resultados encontrados por Hagenauer e Volet (2014). É possível observar que as duas dimensões da qualidade da relação professor-aluno, propostas por estes autores, requerem do professor comportamentos relacionados a identificar as características, necessidades e interesses dos alunos e oferecer ajuda/apoio às diversas necessidades apresentadas por eles. Isso parece envolver, em parte, os comportamentos agrupados nas referidas classes de HS. No entanto, conforme apontam Vieira-Santos e Henkalin (2017), não é incomum ouvir os alunos relatarem sobre as dificuldades que enfrentam no processo de aprendizagem em função da postura coercitiva que alguns dos professores adotam. Segundo esses autores, tais dificuldades são evidenciadas tanto em estudos que observam discrepâncias entre a percepção que alunos e professores possuem sobre o desempenho docente, como no uso de controle aversivo em sala de aula por parte dos professores.

Alguns estudos têm sinalizado que, em parte, a qualidade da relação professor-aluno na Educação Superior pode estar relacionada ao repertório de HS apresentado pelo docente (Vieira-Santos, Del Prette, \& Del Prette, 2018a, 2018b; Vieira-Santos \& Henklain, 2017). Além disso, estudos com professores da Educação Básica têm 
mostrado que o desenvolvimento de HS favorece o diálogo e oportunidades de participação dos alunos em sala (Z. A. P. Del Prette \& Del Prette, 1997; Z. A. P. Del Prette, Del Prette, Garcia, Silva, \& Puntel, 1998) e aumenta a frequência de expressões afetivas do docente para com seus alunos (A. Del Prette, Del Prette, Torres, \& Pontes, 1998). Contudo, Vieira-Santos et al. (2018a) observaram que, apesar de que as HS de docentes universitários ter sido alvo de investigação mais intensa nas últimas décadas, as classes que receberam mais atenção foram as de comunicação, trabalho (principalmente as subclasses "habilidades sociais educativas" e "falar em público") e expressão de sentimentos positivos. Nesse sentido, parece haver a necessidade de mais estudos que investiguem as HS de fazer e manter amizades, sentir e demonstrar empatia e expressar solidariedade.

As HS possuem um caráter situacional-cultural, ou seja, sua apresentação pode ser considerada como adequada ou não em função de variáveis presentes no contexto ou nos desempenhos valorizados por uma determinada cultura ou subcultura (A. Del Prette \& Del Prette, 2010b, 2017a, 2018). Nessa direção, pensando especificamente na oferta de SS mediado por um bom repertório de HS relacionadas à empatia, solidariedade e fazer amizades, é possivel que existam diferenças na percepção que estudantes universitários possuem sobre a oferta de SS por parte de seus professores. Isso poderia ocorrer devido as características presentes no contexto educacional, tais como a natureza da Instituições de Educação Superior (IES), a área de conhecimento a qual pertence o curso que o aluno está realizando, o momento do curso em que o aluno se encontra, o papel desempenhado pelo professor na relação com o aluno e o sexo do professor avaliado.

Em relação à natureza da IES, Vieira-Santos e Henklain (2017) sinalizam que o professor de IES pública, na maioria das vezes, assume distintos papéis (docente, pesquisador, gestor e responsável pela oferta de programas de extensão) e, portanto, necessita dividir seu tempo para atender as demandas envolvidas em cada um deles. Esses autores também ressaltam o fato de que o professor de IES pública também precisam lidar com a pressão do produtivismo acadêmico e com a maior valorização do investimento em pesquisa (seja pela instituição, por pares e/ou por agências de fomento) do que em docência.

Aliado a isso, segundo Almeida, Marinho-Araujo, Amaral e Dias (2012), atualmente é possível identificar dois perfis de estudantes universitários: (a) o aluno tradicional, "que se apresenta na faixa etária esperada, tem bom background familiar, recursos financeiros, motivação e segurança na escolha profissional, e um histórico escolar de inclusão social e sucesso acadêmicos" (p. 906); e (b) o aluno novo, que corresponde aquele indivíduo que (...) utiliza parte do seu tempo para sua subsistência e/ou de sua família; é, geralmente, pertencente à primeira geração de longa escolaridade; não dispõe de tempo, espaço e condições apropriadas para estudar; teve e tem pouca aproximação com os artefatos intelectuais e artísticos da cultura hegemônica; tem muitas dificuldades para conciliar o tempo de trabalho com as atividades acadêmicas extra-aula (extensão cultural, pesquisa, encontros científicos); possui pouca motivação, recursos e disposição para relacionamentos, atividades sociais e culturais com outros estudantes (p. 906).

De acordo com esses autores, são os "alunos novos" aqueles que prioritariamente ingressam nas instituições particulares. Assim, dadas as dificuldades que esse grupo de alunos enfrenta para manter-se na Educação Superior, é possível que necessitem de mais SS de seus professores, podendo ser mais críticos quando percepcionam essa insuficiência. Essas diferenças podem afetar a forma como professores de instituições públicas e particulares engajam-se em relações satisfatórias com seus alunos e, consequentemente, no SS oferecido aos alunos. Igualmente podem ser diferentes as percepções dos alunos sobre o SS disponibilizado pelos professores.

Quanto à área do conhecimento que pertence o curso que o aluno está realizando, é possível que haja diferença no SS ofertado por professores de diferentes áreas do conhecimento devido a postura valorizada no futuro profissional. Professores de cursos da área da saúde/biológicas e de humanas - em cuja a relação profissionalcliente/paciente ocupa um lugar de destaque (tais como, Psicologia, Pedagogia, Fisioterapia, Enfermagem, entre outros) no exercício profissional - podem estar mais preocupados com a oferta de SS em função do perfil do 
egresso esperado do que professores de ciências exatas (e. g., Engenharias, Física e Matemática). Assim, professores de cursos da área da saúde/biológicas e de humanas poderiam estar mais atentos ao impacto de seu comportamento sobre seus alunos e, portanto, mais disponíveis para oferecer SS.

Outra variável que pode afetar a oferta de SS diz respeito ao momento em que o aluno se encontra no curso. Ao ingressar na IES, o aluno passa por um período de adaptação à sua nova realidade acadêmica, a qual é distinta da realidade do Ensino Médio (Soares et al., 2014). É provável que, nesse período de adaptação o aluno necessite de mais SS do professor do que o aluno que se encontra em fase mais avançada ou no final do curso.

O papel desempenhado pelo professor na relação com o aluno também pode afetar a forma como o aluno percebe o SS oferecido pelo professor. Professores teóricos - que atuam em sala de aula - apresentam uma maior taxa de alunos/professor, o que pode dificultar a identificação de situações que demandem a oferta de SS aos seus alunos. Já professores que desempenham o papel de supervisor de estágio e/ou orientador de iniciação científica acabam por estabelecer uma relação mais próxima com seus alunos, o que proporciona melhores condições para identificar as dificuldades que o aluno está enfrentando e oferecer SS.

Por fim, devido aos diversos papéis de cuidado que a mulher desempenha ao longo da vida (irmã, mãe, tia, filha) é possível que ela seja mais sensível para identificar situações que exijam a oferta de SS do que homens. Nesse sentido, professoras (mulheres) poderiam oferecer mais SS aos seus alunos do que professores (homens).

A partir do exposto, o presente estudo baseia-se em cinco premissas relevantes: (a) receber SS tem sido apontado como um fator que auxilia o estudante a enfrentar os desafios presentes na Educação Superior e favorece sua permanência na universidade até concluir o curso (López, 2016); (b) uma das tarefas envolvidas no papel de professor é a de criar condições para a aprendizagem e sucesso acadêmico do aluno (Weimer, 2002); (c) o SS está diretamente relacionado a qualidade da relação estabelecida com um outro significativo que se mostra disponível para cuidar, valorizar e fortalecer a percepção de pertencimento do indivíduo (Cobb, 1976; Marôco et al., 2014); (d) a qualidade da relação estabelecida entre duas pessoas depende, entre outros fatores, do repertório de HS que elas possuem (A. Del Prette \& Del Prette, 2010b, 2017a); e (e) as HS de fazer e manter amizades, empatia e solidariedade parecem estar na base dos padrões comportamentais relacionados a oferecer SS a outra pessoa, visto que envolve comportamentos relacionados a demonstrar-se disponível para cuidar, valorizar e fortalecer a percepção de pertencimento do outro. Com base nessas premissas, este estudo buscou verificar a avaliação que estudantes universitários brasileiros fazem do SS ofertado por seus professores, tomando como referência as HS de "fazer e manter amizade", "empatia" e "expressar solidariedade" apresentadas pelos docentes na relação com os discentes. Além disso, também buscou examinar: se existem diferenças na avaliação realizada pelos alunos em função de variáveis do contexto acadêmico, do curso e da relação professor-aluno.

\section{Método}

\section{Participantes}

Participaram deste estudo 1406 estudantes brasileiros, entre 18 e 55 anos $(\bar{x}=22.12, D P=5.19$ anos $)$. A amostra foi composta por $59.4 \%$ de mulheres e $66.1 \%$ de alunos de IES particulares. Em relação ao momento do curso, $36.8 \%$ dos participantes estavam no início do curso ( $1^{\circ}$ ou $2^{\circ}$ semestre), $34.0 \%$ no meio $\left(3^{\circ}\right.$ ao $6^{\circ}$ semestre), $13.7 \%$ no final ( $7^{\circ}$ semestre para frente) e $15.5 \%$ não forneceram essa informação. Quanto à área do curso, os participantes foram divididos em alunos de ciências biológicas (42.4\%), ciências exatas (23.9\%) e ciências humanas $(43.7 \%)$.

\section{Instrumento}

Aplicou-se o Inventário de Habilidades Sociais Educativas do Professor Universitário - versão Aluno (IHSEPU-Aluno; Vieira-Santos, Del Prette, \& Del Prette, 2018c), o qual busca avaliar a percepção que estudantes 
universitários possuem sobre as HS de seus professores. Este instrumento foi escolhido porque avalia as HS a partir da perspectiva do campo teórico-prático das HS, enfatizando a compreensão de que esses comportamentos devem ser analisados a partir do contexto situacional-cultural no qual são apresentados (A. Del Prette \& Del Prette, 2017a). Além disso, o desenvolvimento de um repertório elaborado de HS é visto como um pré-requisito para a apresentação de competência social (A. Del Prette \& Del Prette, 2010b, 2017b).

O IHSE-PU-Aluno encontra-se em fase de avaliação de suas propriedades psicométricas e, versão submetida à análise de suas qualidades psicométricas, possui 62 itens relacionados às HS. Cada item apresenta uma única habilidade e o aluno responde, em uma escala Likert ( $0=$ nunca a $4=$ sempre $)$, com que frequência o professor age daquela maneira.

Dos 62 itens, foram selecionados 10 considerados como representativos do fenômeno denominado como SS. Esses 10 itens foram examinados em função das classes de HS que representavam e das classes de informações envolvidas no SS. Como é possível observar na Tabela 1, os itens parecem abranger tanto as três classes de HS, como as classes de informação envolvidas no SS (Cobb, 1976).

Tabela 1

Classificação dos itens quanto à HS e às informações envolvidas no SS

\begin{tabular}{|c|c|c|}
\hline Item & Habilidade Social & $\begin{array}{c}\text { Informação } \\
\text { envolvidas no SS }\end{array}$ \\
\hline $\begin{array}{l}\text { 02. Quando eu ou algum colega está passando por algum problema, este } \\
\text { professor procura apoiá-lo. }\end{array}$ & Solidariedade & $\mathrm{A}$ \\
\hline $\begin{array}{l}\text { 03. Se algum aluno está feliz por um acontecimento positivo ou conquista, } \\
\text { este professor expressa satisfacão com isso. }\end{array}$ & Empatia & B \\
\hline $\begin{array}{l}\text { 09. Este professor tem um relacionamento amistoso em sala de aula com os } \\
\text { alunos. }\end{array}$ & Fazer e manter amizade & $\mathrm{C}$ \\
\hline $\begin{array}{l}\text { 16. Sinto que posso pedir ajudar a este professor caso precise de conselhos } \\
\text { para tomar decisões acadêmicas ou profissionais. }\end{array}$ & Fazer e manter amizade & A \\
\hline $\begin{array}{l}\text { 19. Este professor nos dá atenção quando lhe contamos alguma coisa } \\
\text { importante. }\end{array}$ & Empatia & B \\
\hline $\begin{array}{l}\text { 20. Este professor nos incentiva a perseverar quando sentimos dificuldade } \\
\text { em realizar alguma tarefa complicada. }\end{array}$ & Solidariedade & B \\
\hline $\begin{array}{l}\text { 25. O professor conversa com a gente sobre o que pretendemos fazer ou } \\
\text { como pretendemos realizar atividades que estamos planejando (por } \\
\text { exemplo, de estágios). }\end{array}$ & $\begin{array}{l}\text { Empatia } \\
\text { Fazer e manter amizade }\end{array}$ & A \\
\hline $\begin{array}{l}\text { 32. Com este professor, a turma encontra abertura para falar coisas do dia- } \\
\text { a-dia. }\end{array}$ & Fazer e manter amizade & $\mathrm{C}$ \\
\hline 38. As aulas deste professor têm momentos de descontração e brincadeiras. & Fazer e manter amizade & $\mathrm{C}$ \\
\hline $\begin{array}{l}\text { 44. Sinto que posso procurar este professor se preciso de ajuda para } \\
\text { resolver situações da prática profissional. }\end{array}$ & Solidariedade & A \\
\hline
\end{tabular}

Nota: A - Informações que levam a pessoa a crer que é cuidada e amada, B - Informações que permitem que a pessoa acredite que é estimada e valorizada, $\mathrm{C}$ - Informações que fazem com que a pessoa perceba que pertence a uma rede de comunicação e obrigações mútuas.

Além dos itens relacionados às HS, o IHSE-PU-Aluno também possui um campo destinado à caracterização da amostra. Das informações levantadas sobre o perfil dos participantes, foram utilizadas na análise dos dados: (a) natureza da IES, (b) área de conhecimento do curso, (b) momento do curso em que se encontrava o participante e (d) se o professor avaliado era supervisor de estágio ou orientador de iniciação científica ou de monografia do respondente. 


\section{Procedimento}

Após a autorização do Comitê de Ética para Pesquisas com Seres Humanos (protocolo CAAE: 59553616.6.0000.5504), os dados foram coletados entre abril e julho de 2017. A escolha das IES foi realizada por conveniência e a coleta ocorreu em sala de aula, em horário previamente combinado com o professor.

Cada participante respondia individualmente o IHSE-PU-Aluno e avaliava um único professor. Para evitar que o aluno escolhesse o professor com que tinha mais afinidade ou mais desavenças, a pesquisadora utilizou a seguinte estratégia: (a) listava no quadro as disciplinas que a turma estava cursando naquele semestre, sendo que em cada turma eram listadas no quadro até sete disciplinas diferentes que a turma estava cursando; (b) para cada disciplina era atribuída uma letra (entre "A" e "G"); (c) no campo "nome professor" do IHSE-PU-Aluno, a pesquisadora escrevia, previamente, uma das letras utilizadas para representar as disciplinas que a turma estava cursando naquele semestre; (d) as cópias do instrumento eram distribuídas aleatoriamente entre os alunos presentes na sala; e (e) ao receber o instrumento, o participante verificava a letra que estava escrita no campo "nome professor" e respondia ao instrumento pensando no professor que ministrava a disciplina representada por aquela letra (conforme registrado no quadro). Caso a letra correspondesse à uma disciplina que o participante não cursava, ele poderia, então, escolher para avaliar um dos professores das disciplinas que estava cursando naquele semestre. Apenas $5.0 \%$ dos alunos escolheram o professor que iriam avaliar.

Os alunos foram informados que a participação na pesquisa era voluntária, anônima e que podiam abandoná-la a qualquer momento que quisessem. Também foi assegurado que, em hipótese alguma, os professores avaliados teriam acessos aos instrumentos preenchidos. Os participantes expressaram o consentimento em participar da pesquisa mediante a assinatura do Termo de Consentimento Livre e Esclarecido (TCLE).

Foram examinados 10 itens do IHSE-PU-Aluno que estão relacionados ao SS. Os dados foram tratados utilizando o pacote Statistical Package for the Social Science (SPSS) versão 20 e três análises foram realizadas: (a) verificação da unidimensionalidade do conjunto de itens; (b) análise da variância em função das variáveis natureza da IES (pública ou particular), momento do curso (início, meio ou final), área de conhecimento do curso (humanas, biológicas ou exatas) e papel do professor (supervisor/orientador ou professor teórico/de sala de aula); e (c) análise das diferenças na percepção de SS em função do professor ser do mesmo sexo ou do sexo oposto ao do participante.

\section{Resultados}

Dos 10 itens, 80\% apresentaram como mediana as categorias 3 (quase sempre) ou 4 (sempre). Ademais, com exceção do item 25 , todos os demais itens apresentaram média superior a $2(\bar{x}>2)$.

A unidimensionalidade dos itens foi examinada por meio da análise da consistência interna, da comunalidade e do índice de variância explicada. Os dados demonstraram: (a) alta consistência interna $(\alpha=.916)$, (b) comunalidades acima de .500 (exceção: itens 38 e 25 com comunalidade de .458 e .376 respectivamente) e (c) $57.96 \%$ da variância nos dados é explicada pelo conjunto de itens. Tais resultados indicam que esses itens podem ser tratados como uma escala unidimensional, aqui denominada de suporte social.

Em seguida, verificou-se se havia diferença no SS percebido pelos alunos em função de três tipos de variáveis: (a) contexto acadêmico, entendido como a natureza da IES (pública ou particular); (b) curso, aqui incluídas as variáveis área de conhecimento (humanas, biológicas ou exatas) e momento do curso (início, meio e final); e (c) relação professor-aluno, tomando como base o papel desempenhado pelo professor (supervisor/orientador ou professor teórico/de sala de aula). Analisando cada uma dessas variáveis individualmente por meio de Teste $t$ de Student ou ANOVA, foram encontradas diferenças significativas em função da natureza da IES $(t(1404)=$ $-5.274, p=.001)$ e do papel do professor $(t(121.90)=2.209, p=.029)$, mas não quanto ao momento $(F(2,1404)=0.370, p=.691)$ e à área de conhecimento $(F(2,1404)=0.011, p=.989)$. Quando se 
examinou a interação entre as variáveis foram localizadas interações significativas entre: (a) natureza da IES e momento do curso $(F(1,2)=5.821, p=.003)$ e (b) papel do professor e momento do curso $(F(1,2)=4.253$, $p=.014)$.

Em relação à natureza da IES, os alunos de instituições particulares avaliaram que seus professores forneciam mais $\mathrm{SS}(\bar{x}=26.90, D P=9.40)$ do que os alunos de instituições públicas $(\bar{x}=23.98, D P=10.60)$. Além disso, como a amostra de alunos de instituições particulares foi formada por alunos de uma instituição confessional e de outra não confessional, verificou-se também se havia diferenças no SS em função desse aspecto. O Teste $t$ de Student revelou que os alunos da instituição confessional $(\bar{x}=26.19, D P=8.98)$ avaliaram que seus professores ofertavam mais SS do que os alunos da instituição não confessional $(\bar{x}=27.72, D P=9.71)$ e essa diferença foi estatisticamente significativa $(t(922.94)=-2.491, p=.013)$.

Tomando em consideração a interação entre natureza da IES e momento do curso, duas conclusões são possíveis (ver gráfico à esquerda na Figura 1). Primeiro, os alunos de IES particulares que estão no início ou no meio do curso avaliaram que seus professores forneciam mais SS do que alunos de IES públicas. Já, entre os alunos que estão no final do curso, parece não haver diferença significativa em função da natureza da IES. Segundo, ao comparar, dentro de cada tipo de instituição, a avaliação dos alunos no final do curso com a avaliação dos alunos no início e meio, verifica-se que os alunos das instituições públicas recebem mais SS ao final do curso do que os alunos das instituições particulares.
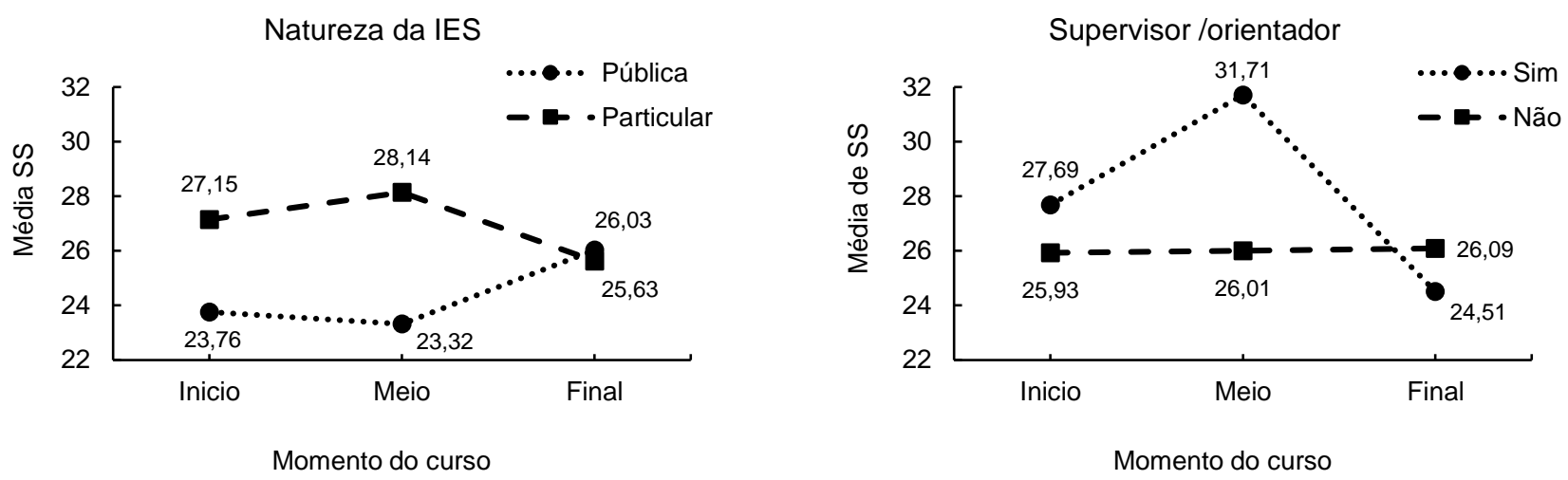

Figura 1. SS percebido em função das variáveis natureza da IES, papel do professor e momento do curso

Já em relação ao papel do professor, os alunos que avaliaram seu supervisor/orientador perceberam receber mais SS $(\bar{x}=27.88, D P=9.48)$ do que os alunos que avaliaram professores que ministram disciplinas teóricas $(\bar{x}=25.73, D P=9.95)$. Além disso, a interação entre o papel do professor e o momento do curso (gráfico à direita da Figura 1) demonstrou que, quando o aluno avalia um professor que ministra disciplinas teóricas, praticamente não existe diferença no SS percebido em função do momento do curso. No entanto, quando o professor avaliado é supervisor/orientador, há diferença em função do momento do curso. Os alunos no meio do curso avaliam receber mais SS de seus supervisores/orientadores do que os alunos do início e do final do curso.

Por fim, se verificou se havia diferenças significativas em função do sexo do aluno e do sexo do professor, ou seja, se existia diferenças quando alunos (homens) avaliavam professoras (mulheres) e alunas (mulheres) avaliavam professores (homens). Os dados da Tabela 2 sugerem que os alunos atribuíram mais SS aos seus professores (independente do sexo) do que as alunas. Contudo, não foram encontradas diferenças significativas em função sexo do professor e/ou do aluno.

Apesar de não haver diferenças significativas quando os itens eram avaliados como uma única dimensão, a análise de cada item em função do sexo do professor permitiu verificar que: (a) professoras (mulheres) parecem 
conversar mais com os alunos sobre o que eles pretendem fazer do que os professores $(U=$ 216782.50, $p=.003$ ); e (b) professores (homens) parecem ter um relacionamento mais amistoso $(U=$ 214958.00; $p=.001)$ e suas aulas são mais descontraídas $(U=208310.50, p=.001)$ do que as professoras. Já quando se toma em consideração a interação entre as variáveis sexo do professor e sexo do aluno, só foram localizadas diferenças estatisticamente significativas no item 2, no qual observou-se que os alunos (homens) avaliam receber mais apoio de suas professoras (mulheres) do que de seus professores $\left(X^{2}(2)=15.680, p=.004\right)$. No entanto, não foram identificadas diferenças estatisticamente significativas, em função do sexo do professor, quando alunas (mulheres) responderam a esse item.

Tabela 2

Suporte social em função do sexo do aluno e do professor

\begin{tabular}{ccccc}
\hline Sexo do & Sexo do & \multicolumn{3}{c}{ Suporte Social } \\
Aluno & Professor & $M$ & $D P$ & $N$ \\
\hline \multirow{2}{*}{ Feminino } & Feminino & 25.65 & 10.12 & 495 \\
& Masculino & 25.68 & 10.16 & 317 \\
\multirow{2}{*}{ Masculino } & Feminino & 26.28 & 9.52 & 185 \\
& Masculino & 26.23 & 9.60 & 366 \\
\hline
\end{tabular}

\section{Discussão}

A análise da unidimensionalidade indicou que o conjunto de itens examinados pode ser considerado como uma escala unidimensional, visto que os itens apresentaram, em sua maioria, comunalidade acima de .500 e que o fator foi composto por mais de sete itens (Izquierdo, Olea, \& Abad, 2014). Além disso, quando o Alpha de Cronbach é maior do que .80, como no caso dos dados aqui apresentados, pode-se inferir que a escala é confiável, ou seja, que reflete de maneira consiste o construto que está avaliando (Field, 2009). Esses dados, em conjunto com a análise apresentada na Tabela 1, parecem sinalizar que a escala pode ser uma medida adequada para avaliar o SS ofertado por professores universitários aos alunos.

A análise da variância permitiu verificar que havia algumas diferenças significativas no SS ofertado pelos professores quando foram consideradas variáveis do contexto acadêmico, do curso e da relação professor-aluno. A primeira diferença identificada diz respeito à natureza da IES. Quando analisada de maneira isolada, observouse que, na percepção dos alunos, os professores de instituições particulares parecem fornecer mais SS aos estudantes do que os professores de instituições públicas. É possível que professores de IES públicas sejam mais exigidos em relação à produção acadêmica e a multiplicidade de funções a serem exercidas, fazendo com que esses tenham menos tempo, energia e reforçadores para disponibilizar SS para seus alunos quando comparados aos professores de instituições privadas.

Vieira-Santos e Henklain (2017) sugerem que um dos fatores que dificultam o engajamento do professor em relações satisfatórias com seus alunos são os aspectos institucionais do contexto acadêmico que "envolvem desde a estrutura física e as normas de conduta docente, definidas pelo estabelecimento de ensino, até a concepção de ensino-aprendizagem e a filosofia educacional adotadas pela instituição" (p. 208). Segundo esses autores, nas IES públicas no Brasil, a multiplicidade de tarefas complexas atribuídas ao professor (ensino, pesquisa, extensão e gestão), bem como dificuldades relacionadas a administrar o tempo para atender tais tarefas, podem dificultar o estabelecimento de relações mais próximas dos alunos o que, consequentemente, interfere no tipo de SS oferecido. Ainda nessa direção, é possível que a diferença encontrada entre os professores de instituições particulares confessionais e não confessionais esteja atrelada às normas de conduta valorizadas em cada instituição. Apenas novos estudos com um número maior de instituições particulares confessionais e não confessionais poderão verificar se tal diferença é consistente ou uma característica particular dessa amostra.

Quando a variável natureza da IES foi examinada em conjunto com outras variáveis, observou-se que a interação com o momento do curso era significativa. Alunos de instituições particulares que estavam no início ou 
no meio do curso julgavam receber mais SS de seus professores do que alunos de instituições públicas. Além disso, pensando em termos de trajetória acadêmica, os alunos de instituições públicas que estavam no final do curso avaliaram que recebiam mais SS dos seus professores do que seus colegas que estavam no início ou no meio do curso. Tais diferenças podem estar relacionadas, em parte, ao perfil dos estudantes, visto que, conforme sugerem Marinho-Araujo et al. (2012), as IES particulares têm absorvido a maior parte dos chamados de "novos alunos", os quais apresentam dificuldades que podem requerer mais SS por parte dos professores.

Além disso, o estudante no início do curso, por estar em uma fase de transição e adaptação à Educação Superior, pode ter avaliado que recebeu mais SS do professor devido a um viés cognitivo relacionado com a relevância que atribuí ao suporte. No início do curso, os professores podem desempenhar um importante papel de informação e apoio emocional nesta transição, o que pode não acontecer da mesma forma nos momentos finais do curso, em que o estudante tem maior autonomia.

A análise da variância também permitiu verificar diferenças estatisticamente significativas em função do papel desempenhado pelo professor. No geral, os professores supervisores/orientadores parecem oferecer mais SS do que os professores que não exercem essa função e esta diferença é mais marcante para os alunos que estão no meio do curso. A percepção dos alunos sobre o maior SS oferecido pelo supervisor/orientador pode ser relacionada a três aspectos. Primeiro, a quantidade de alunos por supervisor/orientador tende a ser menor quando comparada aos professores que ministram aulas teóricas em sala de aula, o que teoricamente permite o estabelecimento de uma relação mais próxima com o aluno e melhores condições para que o professor identifique as dificuldades que o estudante está enfrentando e ofereça SS. Segundo, a relação mais próxima pode contribuir que os alunos tenham uma atitude mais favorável em relação ao professor e, portanto, acabe realizando uma avaliação mais favorável do supervisor/orientador do que dos professores que ministram aulas teóricas em sala de aula. Por fim, o terceiro aspecto refere-se as atividades envolvidas no estágio e/ou iniciação científica, as quais podem requer o engajamento do aluno em atividades mais complexas e/ou mais ligadas a prática profissional e, portanto, podem requerer, de fato, maior SS dos professores quando comparadas às atividades realizadas em disciplinas mais teóricas.

Por fim, quando o SS foi examinado tomando em consideração o sexo do professor e o sexo do aluno, só foram identificadas diferenças estatisticamente significativas em itens isolados. Esperava-se encontrar diferenças significativas no SS oferecido por professoras (mulheres) e professores (homens), visto que em um estudo prévio Vieira-Santos et al. (no prelo) observaram que as professoras apresentaram, na percepção de seus alunos, um nível maior de habilidades de empatia e solidariedade do que os professores.

\section{Considerações Finais}

O objetivo do presente estudo foi verificar, na percepção dos alunos, o SS disponibilizado por professores universitários, tomando como referência as HS dos docentes. As HS envolvidas no desempenho do papel de agente educativo têm sido denominadas, por Z. Del Prette e Del Prette (2010b), como habilidades sociais educativas (HSE) e são definidas como as habilidades sociais que, intencionalmente, promovem o desenvolvimento e a aprendizagem do outro. De acordo com Vieira-Santos, Del Prette e Del Prette (2018d), desenvolver um repertório elaborado de HSE permite que o professor esteja melhor capacitado para oferecer condições que promovam, nos alunos, o desenvolvimento e/ou fortalecimento de padrões comportamentais mais efetivos para atuar frente às diversas demandas com que se deparam.

O ambiente acadêmico tende a valorizar mais o desenvolvimento das capacidades analíticas e instrumentais (A. Del Prette \& Del Prette, 2003) do futuros profissionais. No entanto, a Educação Superior deve contemplar uma visão mais integral de formação, de tal forma que o professor esteja atento aos diversos aspectos do desenvolvimento dos alunos, entre eles a competência social e os valores ético-morais. Nessa direção, os dados do 
presente estudo parecem mostrar que o desenvolvimento das HS relacionadas ao oferecimento de SS aos alunos é um aspecto que deve ser considerado na formação de professores da Educação Superior.

Como toda pesquisa, este estudo também apresenta limitações. Três limitações principais parecem sinalizar possibilidades de futuras investigações. A primeira limitação refere-se ao fato de que a amostragem foi por conveniência e, portanto, a amostra não é representativa da população de estudantes universitários no Brasil. Novos estudos poderiam ampliar a representatividade da amostra em relação às regiões do país, à natureza da IES (públicas e particulares), à filosofia institucional (confessional ou não-confessional), ao momento do curso em que o aluno se encontra (início, meio ou final), à área do curso (humanas, biológicas ou exatas), entre outras variáveis relevantes.

A segunda limitação diz respeito ao fato de que a pesquisa se restringiu à percepção que os alunos têm sobre o SS recebido professores. Contudo, essa percepção do SS pode ser distinta do SS efetivamente fornecido pelos professores (Marôco et al., 2014; Zanini, Verolla-Moura, \& Queiroz, 2009). Assim sendo, futuras pesquisas podem envolver, além da percepção do aluno, a avaliação que os professores fazem sobre o SS oferecido aos alunos e dados de observação da relação professor-aluno dentro do contexto educacional, permitindo uma maior compreensão sobre o SS oferecido pelos professores aos seus alunos.

Por fim, a terceira limitação relaciona-se as condições ofertadas por cada IES. Variáveis como a dimensão da instituição, a quantidade de alunos por turma, a filosofia institucional, o paradigma de atuação docente valorizado pela instituição, a visão que a instituição tem do aluno (cliente ou estudante), entre outras, podem afetar tanto o SS efetivamente ofertado ao aluno como a percepção que o aluno tem do SS percebido. Portanto, novas pesquisas podem ser realizadas no intuito de examinar como essas variáveis afetam a oferta de SS no contexto da Educação Superior.

\section{Referências}

Almeida, L. S., Marinho-Araujo, C. M., Amaral, A., \& Dias, D. (2012). Democratização do acesso e do sucesso no ensino superior: uma reflexão a partir das realidades de Portugal e do Brasil. Avaliação: Revista da Avaliação da Educação Superior (Campinas), 17(3), 899-920. https://doi.org/10.1590/S1414-40772012000300014

Baranovskaya, T. (2015). Self-regulation skills: several ways of helping students develop self-regulated learning. Journal of Language and Education, 1(2), 56-64. https://doi.org/10.17323/2411-7390-2015-1-2-56-64

Cobb, S. (1976). Social support as a moderator of life stress. Psychosomatic Medicine, 38(5), 300-314. https://doi.org/10.1097/00006842-197609000-00003

Del Prette, A., \& Del Prette, Z. A. P. (2003). No contexto da travessia para o ambiente de trabalho: treinamento de habilidades sociais com universitários. Estudos de Psicologia (Natal), 8(3), 413-420. https://doi.org/10.1590/S1413-294X2003000300008

Del Prette, A., \& Del Prette, Z. A. P. (2010a). Programa vivencial de habilidades sociais: características sob a perspectiva da análise do comportamento. In M. R. Garcia, P. R. Abreu, E. N. P. Cillo, P. B. Faleiros, \& P. Piazzon (Eds.), Sobre comportamento e cognição: terapia comportamental e cognitivas (pp. 127-150). Santo André, SP: ESETec.

Del Prette, A., \& Del Prette, Z. A. P. (2010b). Psicologia das relações interpessoais: vivências para o trabalho em grupo ( $8^{\mathrm{a}}$ edição). Petrópolis, RJ: Vozes.

Del Prette, A., \& Del Prette, Z. A. P. (2017a). Competência social e habilidades sociais: manual teórico-prático. Petrópolis, RJ: Vozes.

Del Prette, A., \& Del Prette, Z. A. P. (2017b). O campo das habilidades sociais: conceitos básicos e importância. In Z. A. P. Del Prette \& A. Del Prette (Eds.), Habilidades sociais e competência social para uma vida melhor (pp. 9-24). São Carlos: EdUFSCar. 
Del Prette, A., \& Del Prette, Z. A. P. (2018). A relação entre habilidades sociais e análise do comportamento: história e atualidades. In N. Kienen, S. R. de S. A. Gil, J. C. Lusia, \& J. Gamba (Eds.), Análise do comportamento: conceitos e aplicações a processos educativos clínicos e organizacionais (pp. 39-53). Londrina: UEL. Retrieved from http://www.uel.br/pos/pgac/publicacoes/

Del Prette, A., Del Prette, Z. A. P., Torres, A. C., \& Pontes, A. C. (1998). Efeitos de uma intervenção sobre a topografia das habilidades sociais de professores. Psicologia Escolar e Educacional, 2(1), 11-22. https://doi.org/10.1590/S1413-85571998000100002

Del Prette, Z. A. P., \& Del Prette, A. (1997). Um programa de desenvolvimento de habilidades sociais na formação continuada de professores. In CD-Rom dos trabalhos selecionados para apresentação, 20a. Reunião Anual da ANPED (pp. 1-31). Caxambu, MG: ANPED.

Del Prette, Z. A. P., Del Prette, A., Garcia, F. A., Silva, A. T. B., \& Puntel, L. P. (1998). Habilidades sociais do professor em sala de aula: um estudo de caso. Psicologia: Reflexão e Crítica, 11(3), 591-603. https://doi.org/10.1590/S0102-79721998000300016

Dorrance Hall, E., McNallie, J., Custers, K., Timmermans, E., Wilson, S. R., \& Van den Bulck, J. (2017). A crosscultural examination of the mediating role of family support and parental advice quality on the relationship between family communication patterns and first-year college student adjustment in the United States and Belgium. Communication Research, 44(5), 638-667. https://doi.org/10.1177/0093650216657755

Field, A. (2009). Descobrindo a estatística usando o SPSS (2a). Porto Alegre: Artmed.

Hagenauer, G., \& Volet, S. E. (2014). Teacher-student relationship at university: an important yet underresearched field. Oxford Review of Education, 40(3), 370-388. https://doi.org/10.1080/03054985.2014.921613

Henninger IV, W. R., Eshbaugh, E. M., Osbeck, A., \& Madigan, C. (2016). Perceived social support and roommate status as predictors of college student loneliness. Journal of College \& University Student Housing, 42(2), 4659. Retrieved from http://www.nxtbook.com/nxtbooks/acuho/journal_vol42no2/index.php\#/48

Izquierdo, I., Olea, J., \& Abad, F. J. (2014). Exploratory factor analysis in validation studies: uses and recommendations. Psicothema, 26(3), 395-400. https://doi.org/10.7334/psicothema2013.349

Jesus, L. O. de, Schneider, D. R., Barbosa, L. H., Simon, F., \& Steglich, D. S. (2017). Promoção da Saúde em moradia estudantil: desafios para o fortalecimento da coletividade. Revista Psicologia em Pesquisa, 11(2), 7078. https://doi.org/10.24879/2017001100200167

López, Z. M. (2016). Apoio social percebido e axuste nos estudantes universitarios de primeiro ano. Universidade de Santiago de Compostela.

Marinho-Araujo, C. M., \& Almeida, L. S. (2016). Abordagem de competências, desenvolvimento humano e educação superior. Psicologia: Teoria e Pesquisa, 32(spe), 1-10. https://doi.org/10.1590/0102-3772e32ne212

Marôco, J. P., Campos, J. A. D. B., Vinagre, M. G., \& Pais-Ribeiro, J. L. (2014). Adaptação transcultural BrasilPortugal da escala de satisfação com o suporte social para estudantes do Ensino Superior. Psicologia: Reflexão e Crítica, 27(2), 247-256. https://doi.org/10.1590/1678-7153.201427205

Matta, C. M. B., Lebrão, S. M. G., \& Heleno, M. G. V. (2017). Adaptação, rendimento, evasão e vivências acadêmicas no ensino superior: revisão da literatura. Psicologia Escolar e Educacional, 21(3), 583-591. https://doi.org/10.1590/2175-3539/2017/0213111118

Oliveira, C. T., Wiles, J. M., Fiorin, P. C., \& Dias, A. C. G. (2014). Percepções de estudantes universitários sobre a relação professor-aluno. Psicologia Escolar e Educacional, 18(2), 239-246. https://doi.org/10.1590/21753539/2014/0182739

Pascarella, E. T., \& Terenzini, P. T. (2005). How college affects students: a third decade of research (2nd ed.). San Francisco, CA: Jossey-Bass.

Sarason, I. G., Levine, H. M., Basham, R. B., \& Sarason, B. R. (1983). Assessing social support: The Social 
Support Questionnaire. Journal of Personality and Social Psychology, 44(1), 127-139. https://doi.org/10.1037/ 0022-3514.44.1.127

Soares, A. B., Francischetto, V., Dutra, B. M., Miranda, J. M., Nogueira, C. C. C., Leme, V. R., ... Almeida, L. S. (2014). O impacto das expectativas na adaptação acadêmica dos estudantes no Ensino Superior. Psico-USF, 19(1), 49-60. https://doi.org/10.1590/S1413-82712014000100006

Strom, R. E., \& Savage, M. W. (2014). Assessing the relationships between perceived support from close others, goal commitment, and persistence decisions at the college level. Journal of College Student Development, 55(6), 531-547. https://doi.org/10.1353/csd.2014.0064

Vieira-Santos, J., Del Prette, A., \& Del Prette, Z. A. P. (2018a). Habilidades sociais de docentes universitários: uma revisão sistemática da literatura. Acta Scientiarum. Education, 40(3), 35253. https://doi.org/10.4025/ actascieduc.v40i3.35253

Vieira-Santos, J., Del Prette, A., \& Del Prette, Z. A. P. (2018b). Habilidades sociais educativas de docentes universitários e sua correlação com a satisfação dos estudantes com a relação professor-aluno. In Asociación Española de Psicología Conductual (AEPC) (Ed.), Libro de Actas del 6th International Congress of Educational Sciences and Development (p. 686). Setúbal: Facultad de Psicología, Universidad de Granada.

Vieira-Santos, J., Del Prette, A., \& Del Prette, Z. A. P. (2018c). Inventário de Habilidades Sociais Educativas do Professor Universitário - versão aluno (IHSE-PU-Aluno): dados preliminares. Avaliação Psicológica, 17(2), 260-270. https://doi.org/10.15689/ap.2018.1702.14611.12

Vieira-Santos, J., Del Prette, Z. A. P., \& Del Prette, A. (2018d). Habilidades sociais educativas: revisão da produção brasileira. Avances en Psicología Latinoamericana, 36(1), 45-63. https://doi.org/10.12804/revistas. urosario.edu.co/apl/a.5069

Vieira-Santos, J., \& Henklain, M. H. O. (2017). Contingências sociais que dificultam o engajamento do professor universitário em relações de qualidade com seus alunos. Revista Perspectivas, 08(02), 200-214. https://doi.org/10.18761/PAC.2016.032b

Weimer, M. (2002). Learner-centered teaching: five key changes to practice (1st ed.). San Francisco, CA: JosseyBass.

Zanini, D. S., Verolla-Moura, A., \& Queiroz, I. P. de A. R. (2009). Apoio social: aspectos da validade de constructo em estudantes universitários. Psicologia em Estudo, 14(1), 195-202. https://doi.org/10.1590/S1413-73722 009000100023

Fecha de recepción: 15 de octubre de 2018. Fecha de revisión: 26 de abril de 2019. Fecha de aceptación: 16 de mayo de 2019. Fecha de publicación: 1 de julio de 2019. 